IZA DP No. 6642

Aging and Attitudes Towards Strategic Uncertainty and Competition: An Artefactual Field Experiment in a Swiss Bank

Thierry Madies Marie Claire Villeval Malgorzata Wasmer

June 2012 


\title{
Aging and Attitudes Towards Strategic Uncertainty and Competition: An Artefactual Field Experiment in a Swiss Bank
}

\author{
Thierry Madies \\ University of Fribourg \\ Marie Claire Villeval \\ University of Lyon, CNRS-GATE \\ and IZA \\ Malgorzata Wasmer \\ University of Fribourg \\ Discussion Paper No. 6642 \\ June 2012 \\ IZA \\ P.O. Box 7240 \\ 53072 Bonn \\ Germany \\ Phone: +49-228-3894-0 \\ Fax: +49-228-3894-180 \\ E-mail: iza@iza.org
}

Any opinions expressed here are those of the author(s) and not those of IZA. Research published in this series may include views on policy, but the institute itself takes no institutional policy positions.

The Institute for the Study of Labor (IZA) in Bonn is a local and virtual international research center and a place of communication between science, politics and business. IZA is an independent nonprofit organization supported by Deutsche Post Foundation. The center is associated with the University of Bonn and offers a stimulating research environment through its international network, workshops and conferences, data service, project support, research visits and doctoral program. IZA engages in (i) original and internationally competitive research in all fields of labor economics, (ii) development of policy concepts, and (iii) dissemination of research results and concepts to the interested public.

IZA Discussion Papers often represent preliminary work and are circulated to encourage discussion. Citation of such a paper should account for its provisional character. A revised version may be available directly from the author. 


\section{ABSTRACT}

\section{Aging and Attitudes Towards Strategic Uncertainty and Competition: An Artefactual Field Experiment in a Swiss Bank ${ }^{*}$}

We study the attitudes of junior and senior employees towards strategic uncertainty and competition, by means of a market entry game inspired by Camerer and Lovallo (1999). Seniors exhibit higher entry rates compared to juniors, especially when earnings depend on relative performance. This difference persists after controlling for attitudes towards nonstrategic uncertainty and for beliefs on others' competitiveness and ability. Social image matters, as evidenced by the fact that seniors enter more when they predict others enter more and when they are matched with a majority of juniors. This contradicts the stereotype of risk averse and less competitive older employees.

JEL Classification: C91, D83, J14, J24, M5

Keywords: $\quad$ aging, risk, ambiguity, competitiveness, self-image, confidence, experiment

Corresponding author:

Marie Claire Villeval

GATE (Groupe d'Analyse et de Théorie Economique)

CNRS - University of Lyon

93, Chemin des Mouilles

69130 Ecully

France

E-mail: villeval@gate.cnrs.fr

\footnotetext{
* The authors are grateful to J. Brandts, G. Charness, D. Houser, A. Poulsen, D. Zizzo, and participants at the Interdisciplinary Workshop in Behavioral and Decision Science at Nanyang University in Singapore, at the conference on Deception, Incentives and Behavior at the University of California at San Diego, at the GATE-SEBA workshop in Beijing, at the workshop on Conflicts in Rennes, and at seminars at the University of East Anglia and at the University of Besançon for useful comments. They thank R. Zeiliger for programming the experiment. Financial support from the Agence Nationale de la Recherche (ANR BLAN07-3_185547 "EMIR" project and ANR-EMCO11 "HEIDI" project) is gratefully acknowledged.
} 


\section{INTRODUCTION}

The increasing cost of pension schemes, the dismantling of early retirement plans, and the longterm consequences of declining birth rates create a pressure to maintain older employees at work. However, when it comes to hiring decisions, firms usually prefer recruiting younger workers than older workers, although they appreciate the experience, loyalty and low turnover of senior employees. The unemployment rate of older workers is lower than that of younger workers but if they lose their job, older employees have lower chance of finding another job. As a consequence, older workers tend to be disproportionately represented among the long-term unemployed and have a lower employability (Johnson and Zimmermann, 1993; Disney, 1996; Boersch-Supan, 2001; Chan and Stevens, 2001; OECD 2004, 2006; Riach and Rich, 2006).

Considering the major economic stake that represents the employment of older workers, it is crucial to improve our knowledge of the productivity of these workers relative to other age categories. On the one hand, with the development of information and communication technologies, older workers have been especially concerned with skill obsolescence and a devaluation of their accumulated experience. Moreover, the massive use of early retirement plans has contributed to develop the idea that seniors are less adaptable (Taylor and Walker, 1998; Nelson, 2002). On the other hand, the new knowledge-based organizations require not only up-to-date technical skills but also decision-making skills and cognitive and organizational abilities to cope with increased uncertainty in more volatile and complex environments, for which we do not know the impact of age. Recent studies deliver contradictory evidence on differences in economic decision-making between juniors and seniors. Some of them show that older people

use heuristics leading to more suboptimal choices than younger people in decision situations with multiple options (Agarwal et al., 2010; Besedes et al. 2010; see also Finucane et al., 2002; and 
Abaluk and Gruber, 2011). Others studies conclude that the cognitive abilities of seniors in strategic reasoning are not deteriorated (Kovalchik et al., 2005). ${ }^{1}$ Seniors are no more risk averse than juniors facing lottery choices (Charness and Villeval, 2009). However, the impact of aging on attitudes towards strategic uncertainty remains underexplored. For example, as far as we are aware of, only two economic studies have analyzed aging and competition. While Garatt et al. (2011) have observed that older men have a lower propensity to compete in highly competitive elite races, Charness and Villeval (2009) have found in a two-person real-effort task that older employees respond to competition as strongly as younger participants. ${ }^{23}$

The primary objective of this study is to investigate whether younger and older individuals (that we will name "juniors" and "seniors" for commodity hereafter) differ in their attitudes towards strategic uncertainty when their chance of succeeding in a competitive environment depends either on chance or on their relative ability, and for which reasons. Since both age categories tend to interact in the workplace, our second objective is to study whether the age composition of the pool of potential competitors conditions behavior and influences the overall efficiency of decisions regarding strategic uncertainty. Our results also contribute to the debates on the links between demographic diversity at the workplace and efficiency (Hamilton et al., 2003; Grund and Westergård-Nielsen, 2005; Page, 2007).

\footnotetext{
${ }^{1}$ For recent analyses in the neuroeconomics of age relating economic decision-making, dopaminergic and serotonergic neuromodulation and aging, see Mohr et al. (2010); see also MacPherson et al. (2002).

${ }^{2}$ In Charness and Villeval (2009) competitiveness is measured through the choice between a piece-rate pay scheme and entering a tournament, before solving anagrams in a limited amount of time. Our current design differs from their study in that we consider larger groups, there is no time constraint and competitiveness is measured by means of a market entry decision. Our design also differs from the field data analysis of Garatt et al. (2011), who measure the competitiveness of runners through their choice of entering or not an elite race with prizes for the top runners, in that using a laboratory experiment, we are able to measure beliefs and risk attitudes and manipulate the market size.

${ }^{3}$ Other behavioral studies show that older people tend to be more reciprocal (Fehr et al., 2003; Bellemare and Krüger, 2003; Sutter and Kocher, 2004) but less trustful (Holm and Nystedt, 2005). They are also more cooperative than juniors in public good games (Charness and Villeval, 2009).
} 
To this purpose we conducted a controlled artefactual field experiment (Harrison and List, 2004) using the standard techniques of laboratory experiments with a non-standard pool of participants. This experiment involved employees of a Swiss bank holding the same occupation (client advisors) but belonging to different age categories. The experimental design is based on a market entry game inspired by Camerer and Lovallo (1999), adjusted to study the differences in risk-taking between age categories and complemented by measures of confidence. In our experiment, the junior participants and senior participants make simultaneous market entry decisions knowing the composition of their group in terms of age categories. Given the limited pre-announced market capacity, only well-ranked players can realize profits by entering the market, while entry beyond the capacity generates losses. Depending on the "Random" or "Performance" treatment, the rank of entrants is assigned either randomly, or according to the players' relative performance in a general economic knowledge quiz. The experimental design allows us to study the players' behavior facing strategic uncertainty -that is uncertainty regarding the actions and beliefs of others- and to which extent the decision to enter the market depends on one's attitudes towards risk and uncertainty in general (i.e. in the absence of any strategic consideration), on beliefs about others' willingness to compete and about one's relative ability. We measure whether age categories differ in their decisions, beliefs and confidence levels and whether decisions and beliefs are conditional on the age composition of the groups.

Our results show that seniors enter the market significantly more often than juniors when ranking depends on performance and when ranks are randomly assigned provided the market capacity is larger. We estimate a model of entry decision in order to explain this age gap. First of all, we analyze whether entry in the game (which represents strategic uncertainty) is affected by preferences regarding non-strategic risk and uncertainty. We do not find any intergenerational 
difference in these attitudes in a non-strategic environment, but we observe that the attitudes towards non-strategic risk influence more juniors' than seniors' entry decisions, while the attitudes towards non-strategic uncertainty influence more seniors' than juniors' decisions.

Next, we test whether seniors enter more than juniors because they fail to appreciate more than them the degree of competitiveness of their group members (the "competitive blind spots" in Camerer and Lovallo, 1999). We find that seniors underestimate the willingness of others to enter, especially that of juniors. But, strikingly, we also observe that the higher the number of predicted entrants beyond market capacity, the more often seniors decide to enter the competition.

Then, we study how age categories differ in their confidence in their relative ability as it may influence the entry decisions. Both juniors and seniors enter the market in a greater number in the Performance than in the Random treatment, which denotes a higher confidence in one's relative performance than in a random draw. This effect is stronger for juniors. We also measure the confidence of the participants after they performed the quiz. Although some studies show that knowledge acquired with age leads people to better estimate their relative competence (Kitchner and Brenner, 1990; Russo and Schoemaker, 1992; Peters et al., 2007), we find that compared to juniors, seniors have a lower self-perception. Still, seniors believe to be better ranked than juniors while there is in fact no difference in ability between age groups.

Finally, we examine whether the entry gap between age categories could be driven by image concerns and group identity. Burks et al. (2010) suggest that people might behave overconfidently in order to signal a positive image of themselves to others (see also Benabou and Tirole, 2002). By competing in a greater number than juniors especially in the Performance treatment, controlling for beliefs on ability and others' entry decisions, seniors may be willing to signal that their age category is not afraid of competing. This could explain that their likelihood 
of entry increases with their prediction of a higher number of entrants. The fact that they enter more in the presence of a majority of juniors could be driven by an in-group - out-group effect (Tajfel et al., 1971; Chen and Li, 2009) in the sense that they may be more willing to compete against out-groups than against in-groups.

Even after controlling for risk preferences, beliefs about others' entry decisions and beliefs about one's relative ability, the generational difference in entry remains significant. Since for some market capacities entry is always rational from a theoretical point of view, this remaining effect of age indicates that in our experiment seniors, who enter more, had a better judgment of the situation than juniors on average while juniors use (weakly) dominated strategies more often than seniors. Overall, this study shows that seniors do not take less risk and are not less competitive than juniors. Their profits are similar to those made by juniors. Finally, we find that the gains are highest when groups are balanced in terms of age categories, which suggests that companies should compose diversified teams in terms of age.

The remainder of this paper is organized as follows. Section 2 presents our experimental design, predictions and procedures. Section 3 develops our results. Section 4 discusses the results and concludes.

\section{EXPERIMENTAL DESIGN AND PROCEDURES}

\subsection{The tasks}

Each experimental session is comprised of five parts. Its main part consists of a market entry game inspired from Camerer and Lovallo (1999) that we adjusted to study the differences in decisions between age categories when players are informed on the age categories of their potential competitors. This game is played in the second part of the session. To study their 
influence on decisions in the entry game, we elicit attitudes towards non-strategic risk and uncertainty in the first part of the session. The final three parts of the session are designed to measure the participants' ability, their beliefs about their absolute and relative ability and about the competitiveness of the two age categories involved in this experiment, and their concern for social image. For clarity, we expose the five parts in a chronological order.

\section{$\underline{\text { A test of attitudes towards non-strategic risk and uncertainty }}$}

In the first part, we elicited our participants' attitudes toward non-strategic risk and uncertainty by asking them to choose between certain amounts and drawing a ball from an urn (see Fox and Tversky, 1995, and Appendix 1). Precisely, the participants make a first set of 20 decisions between accepting a certain payoff and extracting a ball from an urn. The composition of the urn is common knowledge ( 5 blue balls and 5 yellow balls). One yellow ball drawn from the urn pays 500 ECU (Experimental Currency Unit, with $100 \mathrm{ECU}=\mathrm{CHF} 2=\mathrm{U} . \mathrm{S} . \$ 2.06$ ), a blue ball pays nothing. The amount of the certain payoff increases from 25 to 500 ECU. Then, the participants make a second set of 20 similar decisions, with the same certain amounts, except that the composition of the urn is now unknown. The switching point in the first set of decisions informs us about the participants' attitude towards non-strategic risk and the difference in switching points between the risky and the ambiguous lotteries indicates their attitude regarding non-strategic uncertainty. ${ }^{4}$ The outcome of these decisions is determined only at the end of the session. One decision in each set of decisions is randomly drawn for payment.

\footnotetext{
4 A risk neutral participant should choose the random draw until the certain payoff is equal to 250 ECU and then select the certain payoff from the $11^{\text {th }}$ decision on. A risk averse (risk-seeking, resp.) participant should switch to the certain payoff for certain payoffs lower (higher, resp.) than 250 ECU. An ambiguity averse participant should switch for lower certain amounts in the second set of decisions than in the first set, while an ambiguity-seeking person should switch later.
} 


\section{The market entry game}

To study attitudes towards strategic uncertainty, we use a market entry game that is largely inspired by Camerer and Lovallo (1999). ${ }^{5}$ Since we are also interested in measuring the influence of the age composition of the pool of potential competitors, we manipulate the composition of groups in terms of age.

Each participant is initially endowed with 500 ECU to avoid any net loss. The game consists of two sequences of nine periods each. Each sequence corresponds to one of two treatments, respectively the "Random" and the "Performance" treatments. In half of the sessions, participants played the random treatment first and then the Performance treatment, whereas in the other sessions we reverted this order. Let us describe the Random treatment first. At the beginning of each of the nine periods, participants are teamed in groups of ten and they are informed on the number of juniors and seniors in their group. The number of juniors (seniors, respectively) can be $0,3,5,7$ or 10 . Participants are also told the capacity of the market, i.e. the maximum number of participants who can make profits by entering the market. According to the periods, the capacity, $c$, can be 2,4 or 6 . Payoffs depend on the market capacity, on the entry decision and on the rank among the entrants, as shown in Table 1. A participant who does not enter earns nothing and loses nothing. The top $c$ entrants share $3000 \mathrm{ECU}$, with higher earnings accruing to higherranked entrants. All entrants who rank below the top $c$ lose 500 ECU. For example, if $c=2$, the highest-rank entrant earns 1900 ECU and the second highest-ranked entrant earns 1100 ECU; any lower-ranked entrant loses 500 ECU. In the Random treatment, ranks are assigned randomly to the entrants by the computer program.

\section{(Insert Table 1 about here)}

\footnotetext{
${ }^{5}$ The main differences with the initial entry game are the number of players, the information on the distribution of group members in terms of generation, the payoff matrix, the number of periods, the task used to elicit performance.
} 
After being informed on the capacity of the market and on the group composition, the participants have to forecast the number of entrants in the period. Then, they have to decide simultaneously on entering or not. At the end of the period, the only feedback each player gets is the total number of entrants (entrants get no feedback on their rank). After each period, groups are re-matched so that the players experience various group compositions.

The Performance treatment is similar to the Random treatment, except that entrants are ranked according to their relative performance in a quiz. Like in Camerer and Lovallo (1999), participants took the quiz after the market entry game and not before, so that entry decisions involve a very general a priori belief of participants on their relative competence. When they make their decisions, participants only know that the quiz will consist of four questions related to general economic knowledge. ${ }^{6}$ They are also shown two examples of questions. The purpose of this design is to analyze how players deal with strategic uncertainty under the veil of ignorance. Since they do not have answered the quiz yet, all the players are treated similarly and their decisions depend only on their beliefs and confidence about their relative knowledge.

The forecasts about the number of entrants inform us about how players adjust their behavior to their perception of others' competitiveness. The comparison of entry decisions in the two treatments, controlling for these forecasts, allows us to measure how the beliefs about one's relative performance influence behavior. Specifically, if a participant is more likely to enter in the Performance than in the Random treatment for given market capacity and forecast of others' decisions, it means that he believes he is better than random others.

\footnotetext{
${ }^{6}$ We chose a general economic knowledge quiz because we thought that all the employees of the bank participating in the experiment would have a similar knowledge and comparable interest in this field regardless of their age, in particular because they self-selected in the same occupation.
} 
This design also allows us to measure whether individuals condition their decisions on the characteristics of their own age category and on the age category of their co-participants, and whether this conditioning depends on the participant's age category. For example, if risk-averse participants believe that juniors are risk seeking, they should enter less the more juniors there are in their group. Overall, if seniors are more confident than juniors, they should enter more in the Performance than in the Random treatment, and more so than juniors, other things equal.

At the end of the experiment, one period out of the 18 is drawn randomly for payment. The computer program calculates the number of entrants and determines their rank. A participant is paid $100 \mathrm{ECU}$ if his forecast regarding the number of entrants in this period was accurate, plus his payoff from his decision. Entrants are informed on their rank. No information is given on whether this period belonged to the Random or the Performance treatment because we are also interested in testing whether participants are willing to preserve their self-image (see below).

\section{The measurement of ability and confidence}

A brief incentivized quiz is used in the third part to determine ability and the ranks in the market entry game. ${ }^{7}$ This quiz includes four questions related to general economic knowledge. ${ }^{8}$ All the players receive the same questions in the same order. The answers can take any value between 0 and 100. Participants have also to indicate an interval of confidence for each answer, i.e. a

\footnotetext{
${ }^{7}$ Typically in the literature on overconfidence, tests of (mis)calibration require the individuals to determine confidence intervals at the $10 \%, 50 \%$ and $90 \%$ levels and to predict their number of correct answers (Dargnies and Hollard, 2009; Cesarini et al., 2006; Juslin et al., 2000; Russo and Schoemaker, 1992). Other tests propose the participants to bet on their knowledge (Blavatskyy, 2009; Goodie A. S., 2005; Fischoff et al., 1977). Many tests of confidence in psychology do not involve incentives but only self-reports (see for example Svenson, 1981).

${ }^{8}$ Questions have been chosen such that most participants working in the financial sector have an idea of the correct answer, but an imprecise one. The questions are: How many countries are members of OECD? What was the Swiss public debt as a percentage of GDP in 2009? What was the proportion of Swiss people with a high degree of satisfaction with life in general in 2006 (in percentage)? What was the share of Swiss exports (as percentage of total exports) to EU 27 in 2009 ?
} 
minimum value such that they believe the correct answer cannot be lower and a maximum value such that they believe the correct answer cannot be higher than this value.

Payoffs are determined in a loss frame. For each question, the participant receives 100 ECU. If the correct answer falls outside of the interval defined by the participant, the $100 \mathrm{ECU}$ are lost. If not, the payoff is given by the difference between $100 \mathrm{ECU}$ and the size of this interval. Maximum payoff is reached when the participant gives the correct answer and sets both the lower and the upper bounds of the interval equal to this answer. This procedure motivates participants to give their best possible answer. It creates a trade-off between giving a smaller interval to earn more ECU, provided it includes the correct answer, and choosing a larger interval to increase the chance that it contains the correct answer. An overconfident (underconfident) risk-neutral participant should indicate a narrower (larger) interval than a well-calibrated participant. Participants in this part earn the sum of payoffs obtained for each question. ${ }^{9}$

The answers determine the player's "distance index", which is our measure of ability. This index is the mean absolute difference between the correct answers and the answers given in the quiz (i.e., a lower distance index indicates more precise answers). In the Performance treatment, ranks are determined by the comparison of the entrants' distance indices. The first rank is assigned to the entrant whose index is the lowest, the second rank to the second lowest index, etc. At the end of the experiment, individuals are informed of their distance index only if they have asked for this information in a further part of the experiment.

In the fourth part, we elicit each participant's beliefs regarding his distance index, the average distance index of juniors and seniors in the session, and his ranking in the quiz among the ten participants of his age category and among the 20 participants in the session. Each correct

\footnotetext{
${ }^{9}$ This payment scheme was in line with Dargnies and Hollard (2009), but our procedure differs from theirs in that we do not ask participants to give $10 \%, 50 \%$ or $90 \%$ confidence intervals.
} 
belief pays 50 ECU. Since we expect that reporting precise estimations is difficult, we propose categories of indices and ranks. Indices are grouped by five $(0-5,6-10, \ldots)$ with a last large category (45 and more). Ranks are grouped by two $(1-2,3-4, \ldots)$. The answers inform us on whether the player believes he is more able than the members of his age group and than members of the other age group. Moreover, if the participant believes that the distribution of abilities is similar in the two age groups, he should report a belief on his rank category in the group of 20 that is exactly twice the category reported in the group of 10. If he reports a rank category in the group of 20 that is less (more) than twice the category reported in the group of 10 , this indicates that the participant believes that the participants of the other age group are less (more) able. At the end of the session, participants are informed on their total payoffs for this part.

\section{$\underline{\text { Self image concerns }}$}

Because we hypothesize that a potential age gap in strategic risk-taking behavior could be driven by a concern for self-image, in the fifth part we ask our participants whether they are willing to learn their own distance index in the quiz and their ranking among the 20 participants at the end of the session. Indeed, Koszegi (2006)'s model of ego utility suggests that, due to self-image concerns, individuals who believe they are more able should be less willing to search for additional information on their actual ability than people with less optimistic beliefs because they are more at risk of receiving bad news on their intrinsic value. Since almost all the participants decided to learn their performance, we will no longer refer to this part of the experiment. ${ }^{10}$

\subsection{Predictions}

Under the assumption of risk neutrality, there are several asymmetric Nash equilibria in pure strategy in which $c+5$ or $c+6$ players should enter the market. For $c=2$ and $c=4$, the $c+6^{\text {th }}$ player

\footnotetext{
${ }^{10} 95 \%$ of the seniors and between $97 \%$ and $100 \%$ of the juniors are willing to know their performance in the quiz and their rank. Incidentally, our data, like those of Burks et al., 2010, do not support Koszegi (2006)'s model,.
} 
is indifferent because his expected payoff from entering is 0 . Above $c+6$ entrants, the expected payoff of entry is negative. With our parameter values, all risk-neutral players should enter when $c=4$ and $c=6$, regardless of others' decisions in both treatments. Indeed, the expected payoff of entry is always positive in these cases. In contrast, when $c=2,7$ or 8 players out of 10 should enter; in the absence of communication, it is much more difficult to coordinate, so we expect that the equilibrium play will be less frequent in this case. This leads to our first hypothesis:

Hypothesis 1: The market capacity influences the entry decision of risk-neutral players.

Risk-averse and ambiguity-averse players may be less willing to enter the market even when $c=4$ or $c=6$. We state the following hypothesis:

Hypothesis 2: Risk- and ambiguity-aversion reduces the likelihood of entry. If seniors have different attitudes towards risk and uncertainty than juniors, their entry rate could differ from that of juniors.

A higher expected number of entrants compared to the market capacity is expected to exert a negative influence on the probability to enter, since more competitors than the capacity reduce the expected profits from entry.

Hypothesis 3: A higher expected number of entrants should reduce the entry of risk-neutral players when $c=2$ and that of risk- and ambiguity-averse players regardless of the market capacity.

If players believe that their ability is in the average, they should behave similarly in the Random and the Performance treatments. In contrast, players who believe that their ability is lower than the average should enter less in the Performance than in the Random treatment for any market capacity. Believing that one is better than the average should not affect the behavior of risk-neutral players when $c>2$ since they should rationally enter regardless of others' decisions. 
Hypothesis 4: Entry rates are lower in the Performance treatment than in the Random treatment if players believe their ability is lower than the average. If seniors have different beliefs about their relative ability, their entry rate should differ from that of juniors.

Controlling for their beliefs about others' entry decisions and ability, individuals who are only motivated by the maximization of their payoff should not be influenced by the age composition of their group in any treatment. In contrast, if age group identity matters, belonging to the minority may lead players to be more competitive if competition is used by groups to maintain a positive social identity by elevating their group above others (as suggested by studies in social psychology, see Tajfel and Turner, 1979, and Kite and Smith-Wagner, 2002). This leads to the following hypothesis.

Hypothesis 5: Controlling for beliefs, the age composition of the group influences the entry decision of players who have a concern for maintaining a positive group image.

\subsection{Experimental procedures in the field}

The experiment involved 80 employees of a large private bank in Lausanne, Switzerland. ${ }^{11} 40$ "juniors" (between 22 and 30 years old, mean=28) and 40 "seniors" (between 48 and 62 years old, mean $=55$ ) participated in a total of four sessions. ${ }^{12} 10$ juniors and 10 seniors participated in each session. ${ }^{13}$ All participants had the same occupation (client advisors), and most of them $(82.5 \%)$ had no supervisory functions. The Human Resources department recruited participants via emails and phone calls from 57 offices located in French-speaking cantons in Switzerland in order to minimize the likelihood that several people interacting daily at work would participate in

\footnotetext{
${ }^{11}$ Crédit Suissse is a Swiss bank and a leading global financial services company, offering clients financial advice in all aspects of private banking, investment banking, and asset management. The headquarters are located in Zurich. It employs 49,900 employees in 405 offices in 55 countries.

${ }^{12} 48$ as a cutout age for being considered as « senior » may seem too young to measure age. However, it was not possible to find a sufficiently large sample of older employees in the firm. That being said, the average age of the participants is higher (55). Finally, it should be noted that in many European countries, 48 is already considered as a relatively old age to get a job on the external labor market.

${ }^{13}$ It has not been possible to balance the proportions of males and females, but these proportions were similar in both generations (there were $68 \%$ of males among juniors and $70 \%$ among seniors).
} 
the same session. The invitation mentioned participation in a scientific experiment initiated and managed by academic researchers during working time. The Human Resources department was aware of not revealing the purpose of the experiment or details of the protocol. We can exclude the existence of a self-selection bias as only one person out of 81 that have been contacted has turned down the invitation.

We reconstituted an experimental laboratory in the bank thanks to our "REGATE Mobile Lab". Mobile partitions separated each seat from the next such that the confidentiality of decisions was guaranteed (see Appendix 2). The experiment was computerized using the REGATE software (Zeiliger, 2000). The sessions were run by the same experimenters in two consecutive days to avoid the dissemination of information. All the instructions were read aloud.

Upon arrival, participants drew a tag from a bag assigning them to a specific terminal. Before signing a consent form, they were reminded that decisions were anonymous, that no individual data would be communicated to the company, and that the earnings made during the session were funded by University research funds. Next, the instructions for the first part were distributed and read aloud (see Appendix 1). After questions were answered in private, participants made their decisions. Then, they received the instructions for the second part that detailed the two treatments. We inverted the order between the Random and Performance treatments in two sessions to control for potential order effects. The participants reported their year of birth and filled out a comprehension questionnaire. Answers were checked individually. At the beginning of each period, individuals were informed on the age composition of their group before being informed on the capacity of the market. ${ }^{14}$ A stranger matching protocol was used.

\footnotetext{
${ }^{14}$ Since the second part consists of 18 periods due to time constraints, we could not observe for each participant his decisions for each market capacity with each group composition in each sequence. Therefore, while all participants
} 
Each new set of instructions was distributed after completion of the previous part. At the end of the session, participants received a feedback on random draws in part 1 and on their payoffs in each paid part. They were informed on their distance index and ranking if in the fifth part they chose to be informed. ${ }^{15}$ Finally, they answered to a post-experimental questionnaire.

Each session lasted between 110 and 120 minutes. On average, the participants earned CHF 45.08 (about \$46.40), with a CHF 15 show-up fee. ${ }^{16}$

\section{RESULTS}

In this Section, we first present summary statistics before providing an econometric analysis of the determinants of the juniors' and seniors' decisions in the market entry game. Finally, we study the efficiency of the participants' decisions.

\subsection{Summary statistics}

Table 2 displays descriptive statistics on participants' characteristics, decisions, and beliefs by age category. ${ }^{17}$

\section{(Insert Table 2 about here)}

Table 2 indicates that the entry rate of seniors is higher than that of juniors both in the Random treatment (68.06\% and 64.17\%, respectively) and in the Performance treatment (70.83\% and $60.56 \%$, respectively), but only the latter difference is statistically significant in a t-test

\footnotetext{
are observed in groups with 5 juniors and 5 seniors, and with 10 juniors or 10 seniors, half of them are observed in groups with 3 juniors and 7 seniors and the other half in groups with 7 juniors and 3 seniors for each market capacity. ${ }^{15}$ Indeed, participants did not receive any information on their payoffs before the end of the session. At the end of the session, the computer program selected one decision in each of the two sets of decisions in the first part and a second draw was made if for the selected decisions the individual had decided to extract a ball from the urn. These payoffs were added to the payoffs from the following parts.

${ }^{16} \mathrm{We}$ acknowledge that this represents a modest amount for bankers. However, we must account for the fact that all the participants were given a half-day leave to participate in the experiment. In addition, in the post-experimental questionnaire, we asked participants to rate the seriousness of their decisions on a scale graduated from 0 to 10 . The average score is 8.83 for both generations. This is an indication that participants took the game seriously.

${ }^{17}$ Note that Table 2 reports the results of two-tailed two-sample t-tests. We also performed Mann-Whitney tests. The levels of significance are exactly the same, except for the reported confidence interval in the quiz that is significant at the $10 \%$ level according to the Mann-Whitney test.
} 
( $p=0.004$, two-tailed). Table 3 displays the percentages of participants in each age category who enter the market in each treatment, for each market capacity and each group composition.

\section{(Insert Table 3 about here)}

Table 3 shows that the entry rate always exceeds the market capacity and that it increases with the market capacity in each treatment and for each age category. Seniors enter the market significantly more frequently than juniors in the Performance treatment when the capacity is medium ( $(\mathrm{c}=4)$ or high $(\mathrm{c}=6)$, but not when it is low $(\mathrm{c}=2)$. The difference between age categories is also significant in the Random treatment when the market capacity is medium. As the equilibria of the game for risk-neutral players predict entry for capacities of 4 and 6 , these data show that, contrary to the belief that seniors would enter less, it is juniors that enter less than predicted. Interestingly, we also find that seniors enter more than juniors when the group includes more juniors than seniors. This is true in both treatments.

For each market capacity, the data show a tendency of seniors to slightly increase their entry rate in the Performance treatment compared with the Random treatment while the opposite is observed for juniors. None of these tendencies are, however, statistically significant.

This preliminary analysis supports our first result:

\section{Result 1. Seniors enter the market more frequently than juniors, especially when entry is less risky and when profits for the entrants depend on the participants' relative performance.}

\subsection{The determinants of the entry decision}

Although in equilibrium risk-neutral players should enter the market regardless of others' decisions and characteristics when the market capacity is above 2, Table 3 has shown deviations from the equilibrium and different entry rates by generation. This could be explained by at least four dimensions: $i$ ) the players' preferences for risk and uncertainty; ii) their beliefs on the 
willingness of others to enter the market; iii) in the Performance treatment their beliefs on their relative ability; iv) and the group composition if belonging to the minority or to the majority generation affects behavior. To study the influence of each dimension, we have estimated a Probit model of the decision to enter the market with robust standard errors and clustering at the individual level to account for the fact that the 80 players made 18 successive decisions. The dataset includes 1440 observations in total. Table 4 displays nine regressions. Column (1) pools the data from both treatments and both generations. The same model is estimated on the subsample of juniors in column (2) and on the sub-sample of seniors in column (3). Columns (4) and (5) report the estimates on the data from the Random treatment and from the Performance treatment separately, pooling the data from both generations, while columns (6) to (9) report the same regressions for each generation separately. Reported values are marginal effects.

The independent variables include dummy variables for the Performance treatment and for belonging to the older age category when appropriate. The degree of risk preference is captured by the number of the decision when the participant switched from the risky lottery to the certain payoff in Part 1. The higher this number, the less risk averse is the individual. The preference towards uncertainty is captured by the difference between the switching points in the risky lottery task and in the ambiguous lottery task. A positive value indicates ambiguity aversion as the participant has switched to the certain equivalent earlier when the composition of the urn was unknown than when it was known.

The independent variables also include the player's belief regarding the number of entrants in his group. As far as the Performance treatment is concerned, two variables capture the beliefs on relative performance. One variable takes the value of the expected rank category in the quiz among the participants of one's age category. The "belief on rank better than other age category" 
variable is the belief that the rank category in the whole population is less than twice the rank category within one's own age category; this dummy variable indicates whether the player believes to be better ranked in the other age category than in his own age category. Moreover, two dummy variables capture the age composition of the group, indicating the presence of a majority of juniors and of a majority of seniors, respectively.

Since the equilibrium of the game is different when the capacity of the market is 2 than when it is higher (as if all players enter, the profits on the market are negative), we have interacted all the previous variables of interest with a dummy variable for the lowest market capacity to analyze whether the players' preferences and beliefs exert a stronger influence in this context. We also include two variables indicating the low and the medium capacities of the market, a time trend and a dummy variable indicating whether the current period is the first of the sequence. Finally, all the regressions control for the players' gender and supervisory function, for the order between treatments, and for multiple switches in the risk elicitation task. Since most of these variables are never significant, we do not report their coefficients to save space.

\section{(Insert Table 4 about here)}

Table 4 shows that the likelihood of market entry is affected by the capacity of the market, as predicted by Hypothesis 1. Ceteris paribus, confirming Result 1, entry is more likely for seniors than for juniors except in the Random treatment when the market capacity is low (see columns (1), (4) and (5)). Entry is affected by preferences, beliefs, and group composition. In the following sub-sections, we examine the impact of each dimension successively.

\section{Preferences regarding non-strategic risk and uncertainty}

The elicitation of preferences regarding risk and uncertainty in the first part has shown that only $15 \%$ of juniors and $20 \%$ of seniors can be qualified as risk-averse while $62.50 \%$ of juniors and 
$55 \%$ of seniors are ambiguity-averse as they switch to the certain payoff earlier in the situation of ambiguity. ${ }^{18}$ Table 2 shows that there is no statistically significant difference between juniors and seniors when dealing with non-strategic risk or uncertainty. ${ }^{19}$ By a different elicitation method, this confirms the findings of Charness and Villeval (2009). Table 4 reveals, however, that these preferences exert a different influence on juniors and seniors when uncertainty becomes strategic. A higher degree of risk-loving preferences significantly increases juniors' likelihood of entry, while it moderately affects seniors (see column (7)). In contrast, ambiguity aversion significantly decreases the seniors' likelihood of entry, especially in the Performance treatment, while it moderately affects the decisions of juniors (column (6)). The marginal effect of a higher degree of risk-loving preferences on juniors' decisions is larger $(0.030)$ than the effect of ambiguity aversion on seniors' decisions (-0.014) (see columns (2) and (3)).

This leads to our second result that supports and complements Hypothesis 2.

Result 2. While juniors and seniors exhibit the same preferences towards non-strategic risk and uncertainty, the likelihood of entry is increased by a higher preference for risk of juniors and decreased by the ambiguity aversion of seniors.

\section{Beliefs on others' willingness to enter}

Although people enter less than the equilibria would predict, we find confirmation in our data of a reference group neglect. When they report their belief about the number of other entrants, $84 \%$ of juniors and $69 \%$ of seniors anticipate a higher number of entrants than the market capacity but $90.14 \%$ of juniors and $88.06 \%$ of seniors predict entry levels that are in fact below the equilibria.

\footnotetext{
${ }^{18}$ These percentages of risk-averse individuals are lower compared to a standard student-subject pool. Using the same elicitation method, Hogarth and Villeval (2009) find that $33.81 \%$ of their students are risk averse and 55.24\% exhibit ambiguity aversion. The difference may be due to the size of incentives in the lottery that are very low relative to the employees' wages, the self-selection of less risk averse individuals in the profession of bankers, and the expertise of bankers for decisions relative to risk. Again, we are more interested in the comparison between age categories within the same population of employees than in the level of risk itself.

${ }^{19}$ Table 2 reports the results of t-tests. Kolmogorov-Smirnov tests deliver the same conclusions.
} 
Table 2 reveals that seniors predict a significantly lower number of entrants beyond the capacity than juniors (1.30 and 1.80, respectively, $p<0.001)$. $50 \%$ of seniors compared to $39 \%$ of juniors underestimate the actual number of entrants. ${ }^{20}$ This underestimation is striking in the Performance treatment when the groups consist of 7 juniors and 3 seniors: $58 \%$ of seniors compared to $36 \%$ of juniors underestimate the number of entrants. Seniors believe that juniors will be less willing to oppose them in this tournament. This is consistent with the fact that they enter more than juniors in this group configuration.

This analysis is completed by an examination of the average expected profits that depend on both the predicted number of entrants and the market capacity. Since the maximal total profit on the market amounts to $3000 \mathrm{ECU}$ (see Table 1), when one forecasts more entrants (including oneself) than the market capacity, the expected profit per entrant is:

$$
E(\Pi)_{i t}=\frac{3000-500 \cdot\left(\text { predicted }^{\text {number of entrants }}{ }_{i t}-\text { market capacity }_{t}\right)}{\text { predicted number of entrants }}
$$

If one forecasts fewer entrants (including oneself) than the market capacity, then the expected average profit is simply the sum of positive profits of all predicted entrants divided by the predicted number of entrants. Table 5 displays the entrants' average expected profits by treatment, generation, and group composition.

\section{(Insert Table 5 about here)}

Table 5 shows that in the Random treatment, senior entrants always await significantly higher gains than junior entrants, regardless of the group composition $(p=0.002)$. In the Performance treatment, the higher the number of juniors in the group, the higher the profit expected by seniors.

\footnotetext{
${ }^{20}$ This mis-prediction of others' entry rate is consistent with the study of Faro and Rottenstreich (2006) that shows evidence of systematic regressive mis-predictions of others' choices under risk. They find that individuals predict that others' decisions are closer to risk neutrality than they actually are, and that risk seeking individuals predict that others are risk seeking but substantially less so.
} 
The discrepancy in anticipated gains between juniors and seniors reaches its maximum when the group consists of 7 juniors and 3 seniors. Then, the average profit expected by junior entrants is only 244 ECU compared to 468 ECU forecasted by senior entrants $(p=0.003)$.

Hence, seniors seem to be more prone to the blind spot bias, especially with respect to the juniors' competitiveness. ${ }^{21}$ Another striking finding is that seniors are significantly more likely to enter when the expected number of competitors on the market is higher: each expected entrant above the capacity increases their entry likelihood by $3.9 \%$ in both treatments with no additional effect when the market capacity is low (columns (7) and (9), Table 4). This variable exerts no impact on the juniors' decisions even when $c=2$. An interpretation is that seniors do not want to look less competitive than others: when they believe that competition is the norm, they enter more. Thus, we can formulate our third result that does not support Hypothesis 3.

Result 3. Seniors expect significantly higher profits from entry than juniors, especially in the Performance treatment when matched with a majority of juniors, because of a tendency to neglect the competitiveness of juniors. Strikingly, seniors are more willing to enter the more they expect others to enter although expected profits decline in the number of entrants.

\section{Beliefs on relative ability}

Table 4 indicates that juniors enter significantly more the market in the Performance than in the Random treatment, while seniors enter more in the Performance treatment only when $c=2$ (columns (2) and (3)). In the Performance treatment the participant's predicted distance index has no significant impact on entry, ${ }^{22}$ in contrast, the likelihood of entry is reduced by more pessimistic beliefs regarding one's performance rank, especially when the market capacity is low.

\footnotetext{
${ }^{21}$ Although they should learn the entry behavior of others through the feedback on the number of entrants received at the end of each period, participants do not change their behavior over time. Indeed, in the regressions reported in Table 4, the time trend is never significant. Only the first period shows sometimes a positive significant effect.

${ }^{22}$ We need to be cautious about this point as beliefs about relative performance were elicited in Part 4 after the participants answered the quiz. When people made their entry decision, they did not know the precise content of the quiz yet. The expected performance when deciding on entry was possibly higher than the post-quiz evaluation.
} 
The impact of beliefs on relative ability is larger for juniors than for seniors: the marginal effect of a higher expected rank category on juniors' entry is -0.165 in general and -0.390 when $c=2$, while for seniors it is -0.243 when $c=2$.

Regarding beliefs about their own ability, seniors are more pessimistic than juniors: $80 \%$ of seniors and $57 \%$ of juniors expect a larger distance index category than the actual one. They are also more pessimistic about their rank in their age category: they expect on average a rank category of 3.33 (a rank category of 3 means an expected rank 5 or 6), while juniors predict a rank category of $2.83(p=0.018)$. Within their own age category, only $32 \%$ of seniors and $45 \%$ of juniors consider themselves as better than the average.

Regarding beliefs about the other age category's ability, both generations predict a larger distance index for juniors. Compared to juniors, seniors make more pessimistic predictions of both juniors' $(p=0.003)$ and seniors' average distance index $(p=0.009$, see Table 2$)$. But only $37.5 \%$ of seniors and $20 \%$ of juniors believe to be better ranked than the other age category. The difference between age categories is not significant $(p=0.233)$, but this variable has an important positive impact on juniors' entry when $c=2$ (see column (2) in Table 4). In contrast to these beliefs, in fact juniors and seniors performed equally well in the quiz $(p=0.761)$ and there is no age difference in actual ranking $(p=0.516)$.

Our next result supports and complements Hypothesis 4:

Result 4. Juniors enter the market in the Performance treatment more often than in the Random treatment. Seniors enter more often in the Performance than in the Random treatment only when $c=2$. Seniors have a lower self-perception and hold more pessimistic beliefs on their rank than juniors but the impact of these beliefs on entry is larger for juniors than for seniors. 


\section{Image motivation and group identity}

The proportion of juniors in groups exerts a significant and positive influence on the decisions of seniors to enter the market while it is not significant for juniors. Table 3 has shown that in both treatments $77.78 \%$ of seniors enter when their group is composed of 7 juniors and 3 seniors, while these percentages are $68.06 \%$ in the Random treatment and $70.83 \%$ in the Performance treatment. Holding beliefs on others' entry decisions and relative ability constant, interacting with a majority of juniors increases the seniors' likelihood of entering by $20.28 \%$ in the Random treatment $(p=0.045)$ and by $23.13 \%$ in the Performance treatment $(p=0.003)$ (columns ( 7 ) and (9) in Table 4). Since the effect is large also in the Random treatment where beliefs on relative performance do not matter, this higher entry rate in the presence of more juniors could be driven by both group identity and social signaling, i.e. the willingness of seniors to signal that, facing juniors, they are not less prone to engage in competition than the younger generation. ${ }^{23}$

This hypothesis of a stronger concern for image in seniors is also supported by the previous result showing that seniors enter more, the more they expect that others will enter. This puzzling behavior from a standard economic perspective can be rationalized if seniors get an additional utility from conforming to signal that they are equally ready to take strategic risks.

This leads to our next result that supports Hypothesis 5:

\section{Result 5. The higher entry rate of seniors, especially when facing a majority of juniors, is also motivated by social signaling and group identity concerns.}

Finally, controlling for the market capacity, risk preferences, beliefs on others' competiveness and on relative ability, group composition, and individual characteristics, we still

\footnotetext{
${ }^{23}$ Note that if group identity may have been strengthened by our design through giving information on the age category of the group members, this design cannot be held responsible for its stronger impact on seniors. Similarly, if seniors' entry decisions were driven by social desirability towards the experimenter, there is no reason why it would be more important when the group is composed with a majority of juniors.
} 
find a significant effect of being a senior on the decision to enter the market when the market capacity is medium or high (see columns (1), (4) and (5) in Table 4). For these capacities, being a senior increases the likelihood of entry by $15.44 \%$ in the Random treatment $(p=0.035)$ and by $24.78 \%$ in the Performance treatment $(p=.005)$. Since for these capacities, the Nash equilibria in pure strategy predict that all the players should enter the market, this residual generation effect might simply capture the fact that seniors dealt better with strategic uncertainty than juniors. ${ }^{24}$

This supports our sixth result:

\section{Result 6. The remaining positive effect of being a senior on the likelihood of entry in both treatments indicates that seniors dealt better with strategic uncertainty than juniors and that juniors used dominated strategies more often than seniors.}

\subsection{Realized payoffs}

Table 6 displays the average per-period realized payoffs in ECU by treatment, generation, and group composition, per participant and per entrant.

\section{(Insert Table 6 about here)}

The comparison of expected payoffs in Table 5 and realized payoffs in Table 6 shows that entrants held excessively optimistic expectations in both treatments: $34.08 \%$ of juniors and $47 \%$ of seniors overestimated expected payoffs. But despite differences in behavior, the payoffs obtained by juniors and seniors differ significantly in neither treatment. Juniors earn less in the Performance than in the Random treatment while the opposite is found for seniors, but none of these tendencies is significant.

Analyzing realized payoffs by group composition, we notice that when groups are mixed, both juniors and seniors realize their lowest mean payoff when their own generation belongs to

\footnotetext{
${ }^{24}$ An alternative interpretation is that seniors have a higher intrinsic taste for competition. We do not retain this interpretation because average entry is always below the equilibria of full entry when capacity is higher than 2 .
} 
the minority. Similarly, they usually realize their maximum payoff when their generation belongs to the majority. In the Performance treatment, senior entrants earn significantly less than juniors in groups composed of 7 juniors and 3 seniors (respectively 71.43 and 362.75 ECU, $p=0.089$ ), and junior entrants earn significantly less than seniors in groups composed of 3 juniors and 7 seniors (respectively -109.09 and 342.62, $p=0.012$ ) although participants from each generation have the same performance ranks.

Finally, Table 6 reveals that when the assignment of ranks is random, payoffs are maximized - and payoff differences between age categories are minimized - when groups are homogenous in terms of generation. In contrast, when the outcome depends on relative performance, payoffs are maximized when groups are mixed and balanced with juniors and seniors in equal proportions. This leads to the last important result:

Result 7. Despite differences in behavior, the realized payoffs of juniors and seniors are similar, except when the age composition of groups is the most unbalanced. In performance tournaments, payoffs are maximized when groups are balanced in terms of age categories.

\section{CONCLUSION}

Our artefactual field experiment attempted at providing novel knowledge on whether younger and older employees differ in their behavior regarding strategic uncertainty and competition by means of a market entry game. One important finding is that, contrary to stereotypes and also to Garatt et al. (2011), seniors exhibit a higher willingness to take strategic risk than juniors, as measured by a higher entry on the market especially when earnings are determined by the relative performance of entrants. Both preferences and beliefs explain this difference in behavior, although both age categories exhibit similar preferences towards risk and uncertainty in a nonstrategic environment and similar ability in a general economic knowledge test. Indeed, the juniors' likelihood of entry is increased by risk seeking while the seniors' likelihood of entry is 
decreased by ambiguity aversion. Regarding beliefs on others' competitiveness, seniors hold higher expectations in terms of return from entry, especially when they belong to a group with a majority of juniors, because they tend to underestimate the others' willingness to enter the market. Regarding beliefs on ability in a general economic knowledge quiz, seniors exhibit a lower self-perception of their relative ability in their age category than juniors and juniors enter more when rank depends on relative performance than when it depends on random drawings.

Another important result is that seniors exhibit a higher willingness to enter the market when they expect a higher entry rate of group members, although this drives the expected profit of entry downwards. In addition, the seniors' willingness to enter the market is increased by the presence of a majority of juniors in the group of potential competitors. This leads us to conjecture that a combination of social signaling and group identity is at play. Indeed, taking more risk in the presence of many competitors could serve seniors to express their intrinsic value, especially when facing a majority of juniors. Incidentally, this suggests that social signaling should be regarded as an additional explanation of entry in this game, in addition to overconfidence (Camerer and Lovallo, 1999) or a feeling of competence (Greco and Hogarth, 2004).

We acknowledge that our study has a number of limitations. In particular, the employees of the company are certainly not representative of the working population. Therefore, we do not pretend to a generalization of our results. However, we believe that these results bring useful insights on some behavioral dimensions that may help in better dealing with the employment of seniors in the labor market. Indeed, better understanding how individuals manage strategic uncertainty is certainly important when assigning responsibilities since it is a component of cognitive abilities. Showing that senior employees deal better with strategic uncertainty suggests that hiring senior employees contributes to the efficiency of firms. 


\section{Reference list}

Abaluk, J., Gruber, J. (2011). Choice Inconsistencies among the Elderly: Evidence from Plan Choice in the Medicare Part D Program. The American Economic Review, 101, 1180-1210.

Agarwal, S., Driscoll, J., Gabaix, X., Laibson D. (2009). The Age of Reason: Financial Decisions over the Life Cycle and Implications for Regulation. Brookings Papers on Economic Activity, Fall, 51-117.

Benabou, R ., Tirole, J. (2002). Self-Confidence and Personal Motivation. The Quarterly Journal of Economics, 117 (3), 261-292.

Bendik, M., Brown, L., and Wall, K. (1999). No Foot in the Door: An Experimental Study of Employment Discrimination Against Older Workers. Journal of Aging \& Social Policy, 10, 523.

Besedes, T., Deck, C., Sarangi, S., Shor, M. (2010). Age Effects and Heuristics in DecisionMaking, mimeo.

Blavatskyy, P.R. (2009). Betting on own knowledge: experimental test of overconfidence. Journal of Risk and Uncertainty, 38, 39-49.

Boersch-Supan, A. (2001). Labor market effects of population ageing. NBER Working Paper 8640 .

Burks, S.V., Carpenter, J.P., Goette, L., Rustichini, A. (2010). Overconfidence is a Social Signaling Bias. IZA Discussion Paper, 4840, Bonn.

Camerer, C. F., Lovallo, D. (1999). Overconfidence and excess entry: An experimental approach. The American Economic Review, 89(1), 306-318.

Cerella, J. (1985), Information Processing Rate in the Elderly. Psychological Bulletin, 98(1), 6783.

Cesarini, D., Sandewall, O., Johannesson, M. (2006). Confidence interval estimation tasks and the economics of overconfidence. Journal of Economic Behavior and Organization, 61, 453470.

Chan, S., Stevens, A.H. (2001). Job Loss and Employment Patterns of Older Workers. Journal of Labor Economics, 19(2), 484-521.

Charness, G., Villeval, M.C. (2009). Cooperation and Competition in Intergenerational Experiments in the Field and in the Laboratory. The American Economic Review, 99(3), 956978.

Chen, Y., Li, S.X. (2009). Group Identity and Social Preferences. The American Economic Review, 99(1), 431-457.

Dargnies, M.P., Hollard, G. (2009). Incentives to learn calibration: a gender-dependent impact. Economics Bulletin, 29(3), 1820-1828.

Disney, R. (1996). Can we afford to grow older? A perspective on the economics of aging. Cambridge, MIT Press.

Einhorn, H. J., Hogarth, R. M. (1986). Decision making under ambiguity. Journal of Business, 59(4), Part 2, S225-S250. 
Faro, D., Rottenstreich, Y. (2006). Affect, Empathy, and Regressive Mispredictions of Others' Preferences Under Risk. Management Science, 52(4), 529-541.

Finucane, M.L., Slovic, P., Hibbard, J.H., Peters, E. , Mertz, C.K., MacGregor, D.G. (2002). Aging and Decision-Making Competence: An Analysis of Comprehension and Consistency Skills in Older Versus Younger Adults Considering Health-Plan Options. Journal of Behavioral Decision Making 15(2), 141-164.

Fischoff, B., Slovic P., Lichtenstein S. (1977). Knowing with certainty: The appropriateness of extreme confidence. Journal of Experimental Psychology: Human Perception and Performance, 3, 552-564.

Fox, C.R., Tversky, A. (1995). Ambiguity Aversion and Comparative Ignorance. The Quarterly Journal of Economics, 110(3), 585-603.

Garatt, R.J., Weinberger, C., Johnson, N. (2011). The State Street Mile: Age and gender Differences in Competition-Aversion in the Field. Forthcoming in Economic Inquiry.

Goodie, S.A. (2005). The Role of Perceived Control and Overconfidence in Pathological Gambling. Journal of Gambling Studies, 21 (4), 481-502.

Grieco, D., Hogarth, R.M. (2004). Excess entry, ambiguity seeking, and competence: An experimental investigation, WP Universitat Pompeu Fabra, Barcelona.

Grund, C., and Westergård-Nielsen, N. (2005). Age Structure of the Workforce and Firm Performance. IZA Discussion Paper 1816, Bonn.

Hamilton, B., Nickerson, J., and Owan, H. (2003). Team Incentives and Worker Heterogeneity: An Empirical Analysis of the Impact of Teams on Productivity and Participation. Journal of Political Economy, 111, 465-497.

Harrison, G. and List, J. (2004). Field Experiment. Journal of Economic Literature, 42, 10131059.

Hogarth, R., Villeval, M.C. (2009). Intermittent Reinforcement and the Persistence of Behavior: Experimental Evidence. IZA Discussion Paper, 5103, Bonn.

Holm, H., and Nystedt, P. (2005). Intra-generational trust - a semi-experimental study of trust among different generations. Journal of Economic Behavior and Organization, 58, 403-419.

Johnson, P., Zimmermann, K. (Eds.) (1993). Labour markets in an ageing Europe. Cambridge, Cambridge University Press.

Juslin P., Winman A., Olsson H. (2000). Naive empiricism and dogmatism in confidence research: A critical examination of the hard-easy effect. Psychological Review, 107, 384-396.

Kite, M.E., Smith-Wagner, L. (2002). Attitudes towards Older Adults. In T.D. Nelson (Ed.), Ageism: Stereotyping and Prejudice Against Older Persons. Cambridge, MIT Press, 129-161.

Koszegi, B. (2006). Ego utility, overconfidence, and task choice. Journal of the European Economic Association, 4 (4), 673-707.

Kovalchik, S., Camerer, C.F., Grether, D.M., Plott, C.R., Allman, J.M. (2005). Aging and Decision-making: A Comparison between Neurologically Healthy Elderly and Young Individuals. Journal of Economic Behavior and Organization, 58(1), 79-94. 
MacPherson, S.E., Phillips, L.H., Della Sala, S. (2002). Age, Executive Function, and Social Decision Making: A Dorsolateral Prefrontal Theory of Cognitive Aging. Psychology and Aging, 17(4), 598-609.

Mohr, P.N.C., Li, S.-C., Heekeren, H.R. (2010). Neuroeconomics and aging: neuromodulation of economic decision-making in old age. Neuroscience \& Biobehavioral Reviews, 34(5), 678688.

Nelson, T. D. (Ed.) (2002). Ageism: stereotyping and prejudice against older persons. Cambridge: MIT Press.

OECD (2004). Paris. Ageing and Employment Policies. Paris.

OECD (2006). Live Longer, Work Longer. Paris.

Page, S.E. (2007). The difference: How the power of diversity creates better groups, firms, schools, and societies. Princeton: Princeton University Press.

Peters, E., Hess, T.M., Västfjäll, D., Auman, C. (2007). Adult Age Differences in Dual Information Processes: Implications for the Role of Affective and Deliberative Processes in Older Adults' Decision Making. Perspectives on Psychological Science, 2(1), 1-23.

Riach, P., and Rich, J. (2006). An Experimental Investigation of Age Discrimination in the French Labour Market. IZA Discussion Paper 2522, Bonn.

Russo J. E., Schoemaker P. J. (1992). Managing overconfidence, Sloan Management Review, 33, $7-17$.

Sutter, M. and Kocher, M. (2007). Trust and Trustworthiness across Different Age Groups. Games and Economic Behavior, 59, 364-382.

Svenson, O. (1981). Are we all less risky and more skillful than our fellow drivers? Acta Psychologica, 1981, 94, 143-148.

Tajfel, H., Billig, M., Bundy, R., Flament, C.L. (1971). Social Categorization and Inter-Group Behavior, European Journal of Social Psychology, 1(2), 149-178.

Tajfel, H., Turner, J. (1979). An Integrative Theory of Intergroup Conflict, in W. G. Austin and S. Worchel (Eds.), The social psychology of intergroup relations, Monterey, CA: Brooks/Cole, 33-47.

Taylor, P., Walker, A. (1998). Policies and practices towards older workers: a framework for comparative research. Human Resources Management Journal, 8(3), 61-76.

Zeiliger, Romain, (2000). A Presentation of Regate, Internet Based Software for Experimental Economics. http://www.gate.cnrs.fr/ zeiliger/regate/RegateIntro.ppt, Lyon: GATE. 
Table 1. Payoff matrix in the market entry game (in ECU)

\begin{tabular}{cccc}
\hline \multirow{2}{*}{$\begin{array}{c}\text { Rank among the } \\
\text { entrants }\end{array}$} & \multicolumn{3}{c}{ Market capacity, $c$} \\
\cline { 2 - 4 } & $c=2$ & $c=4$ & $c=6$ \\
\hline 1 & 1,900 & 1,400 & 900 \\
2 & 1,100 & 900 & 700 \\
3 & -500 & 500 & 500 \\
4 & -500 & 200 & 400 \\
5 & -500 & -500 & 300 \\
6 & -500 & -500 & 200 \\
7 & -500 & -500 & -500 \\
8 & -500 & -500 & -500 \\
9 & -500 & -500 & -500 \\
10 & -500 & -500 & -500 \\
\hline
\end{tabular}

Table 2. Descriptive statistics on decisions, ability, and beliefs

\begin{tabular}{lccc}
\hline & Juniors & Seniors & $p$-values \\
\hline Age & $28.67(.362)$ & $55.28(.571)$ & $.000^{* * *}$ \\
\hline Entry rate (in \%) & $62.36(48.48)$ & $69.44(46.10)$ & $.005^{* * *}$ \\
Entry rate in the Random treatment & $64.17(48.02)$ & $68.06(46.69)$ & .271 \\
Entry rate in the Performance treatment & $60.56(48.94)$ & $70.83(45.52)$ & $.004^{* * *}$ \\
Predicted nb entrants in excess of capacity & $1.80(.050)$ & $1.30(.079)$ & $.000^{* * *}$ \\
\hline Switching point in the risky lottery & $11.19(.410)$ & $12.25(.653)$ & .174 \\
Switching point in the ambiguous lottery & $9.66(.598)$ & $10.28(.740)$ & .514 \\
\hline Distance index in the quiz & $16.15(1.139)$ & $15.68(1.060)$ & .761 \\
Rank among the 20 participants & $10.92(.948)$ & $10.08(.893)$ & .516 \\
Reported confidence interval in the quiz & $23.63(1.207)$ & $21.54(1.529)$ & .289 \\
Belief on one's index & $4.70(.289)$ & $5.80(.378)$ & $.023^{* *}$ \\
Belief on juniors' mean index & $4.83(.248)$ & $6.15(.363)$ & $.003^{* * *}$ \\
Belief on seniors' mean index & $4.60(.306)$ & $5.80(.332)$ & $.009^{* * *}$ \\
Belief on one's rank within own generation & $2.83(.143)$ & $3.33(.149)$ & $.018^{* *}$ \\
Belief on one's rank out of 20 & $5.68(.2887)$ & $6.25(.286)$ & .160 \\
Belief on rank better than other generation & $.25(.069)$ & $.375(.077)$ & .233 \\
\hline Willingness to know one's rank & $1(0)$ & $.95(.035)$ & .156 \\
Willingness to know one's index & $.97(.025)$ & $.95(.035)$ & .562 \\
Acceptance of public exposure & $.95(.035)$ & $.95(.035)$ & 1.0 \\
\hline Profit per period in the entry game (ECU) & $170.56(22.296)$ & $170.42(22.437)$ & .997 \\
\hline
\end{tabular}

Note: Standard deviations in parentheses. $p$-values are for two-tailed two-sample t-tests. Note that beliefs on the distance index are elicited by intervals of five points and beliefs on rank by intervals of two ranks. 
Table 3. Distribution of entry decisions in Part 2 (percentages)

\begin{tabular}{|c|c|c|c|c|c|c|c|c|c|c|}
\hline \multirow{3}{*}{$\begin{array}{l}\text { Group } \\
\text { composit. }\end{array}$} & \multicolumn{10}{|c|}{ Random treatment } \\
\hline & \multicolumn{5}{|c|}{ Juniors } & \multicolumn{5}{|c|}{ Seniors } \\
\hline & $\mathrm{N}$ & Total & $c=2$ & $c=4$ & $c=6$ & $\mathrm{~N}$ & Total & $c=2$ & $c=4$ & $c=6$ \\
\hline $10 \mathrm{~J}$ & 120 & 65.00 & 52.50 & 62.50 & 80.00 & - & - & - & - & - \\
\hline $7 \mathrm{~J}-3 \mathrm{~S}$ & 84 & 59.52 & 39.29 & 57.14 & 82.14 & 36 & $77.78 *$ & 50.00 & 83.33 & 100 \\
\hline $5 \mathrm{~J}-5 \mathrm{~S}$ & 120 & 65.00 & 45.00 & 70.00 & 80.00 & 120 & 69.17 & 37.50 & 82.50 & 87.50 \\
\hline $3 \mathrm{~J}-7 \mathrm{~S}$ & 36 & 69.44 & 66.67 & 50.00 & 91.67 & 84 & 67.86 & 57.14 & 67.86 & 78.57 \\
\hline $10 \mathrm{~S}$ & - & - & - & - & - & 120 & 64.17 & 45.00 & 62.50 & 85.00 \\
\hline \multirow[t]{2}{*}{ All groups } & 360 & 64.17 & 48.33 & 62.50 & 81.67 & 360 & 68.06 & 45.83 & $72.50 *$ & 85.83 \\
\hline & \multicolumn{10}{|c|}{ Performance treatment } \\
\hline $10 \mathrm{~J}$ & 120 & 62.50 & 45.00 & 60.00 & 82.50 & - & - & - & - & - \\
\hline $7 \mathrm{~J}-3 \mathrm{~S}$ & 84 & 60.71 & 42.86 & 60.71 & 78.57 & 36 & $77.78 *$ & 50.00 & $91.17 *$ & 91.67 \\
\hline $5 \mathrm{~J}-5 \mathrm{~S}$ & 120 & 58.33 & 40.00 & 62.50 & 72.50 & 120 & $70.00^{*}$ & 45.00 & $82.50 * *$ & 82.50 \\
\hline $3 \mathrm{~J}-7 \mathrm{~S}$ & 36 & 61.11 & 50.00 & 58.33 & 75.00 & 84 & 72.62 & 64.29 & 64.29 & 89.29 \\
\hline $10 \mathrm{~S}$ & - & - & - & - & - & 120 & 68.33 & 45.00 & 70.00 & 90.00 \\
\hline All groups & 360 & 60.56 & 43.33 & 60.83 & 77.50 & 360 & $70.83 * * *$ & 50.00 & $75.00 * *$ & $87.50 * *$ \\
\hline
\end{tabular}

Note: $\mathrm{N}$ for number of observations, $c$ for market capacity, $\mathrm{J}$ for juniors, and $\mathrm{S}$ for seniors. The numbers in italics indicate when the generation is in minority in the group. Two-tailed two-sample t-tests have been estimated to test the equality of mean entry decisions by generation for each group composition, each market capacity, and each treatment. $* * *$ indicate significance at the .001 level, ** at the .005 level, $*$ at the .10 level. 
Table 4. Determinants of the entry decision in Part 2

\begin{tabular}{|c|c|c|c|c|c|}
\hline $\begin{array}{l}\text { Dependent variable: } \\
\text { Decision to enter }\end{array}$ & $\begin{array}{l}\text { All } \\
(1)\end{array}$ & $\begin{array}{l}\text { Juniors } \\
\text { (2) }\end{array}$ & $\begin{array}{l}\text { Seniors } \\
\text { (3) }\end{array}$ & $\begin{array}{l}\text { Random tr. - All } \\
\text { (4) }\end{array}$ & $\begin{array}{c}\text { Performance tr. - All } \\
\text { (5) }\end{array}$ \\
\hline Performance treatment & $.192(.120) \#$ & $.359 * *(.169)$ & $-.081(.205)$ & - & - \\
\hline Performance treatment $* c=2$ & $.377 * * *(.075)$ & $.365 * *(.163)$ & $.425 * * *(.068)$ & - & - \\
\hline Senior & $.193 * * *(.070)$ & - & - & $.154 * *(.073)$ & $.248 * * *(.088)$ \\
\hline Senior $* c=2$ & $-.181 *(.110)$ & - & - & $-.279 * *(.111)$ & $-.057(.141)$ \\
\hline Risk preferences & $.003(.009)$ & $.030 *(.017)$ & $-.011(.009)$ & $.006(.011)$ & $-.001(.009)$ \\
\hline Risk preferences $* c=2$ & $.027 * *(.013)$ & $.079 * *(.031)$ & $.021(.014)$ & $.033 * *(.015)$ & $.022 *(.014)$ \\
\hline Ambiguity aversion & $-.011(.008)$ & $-.002(.013)$ & $-.014 *(.008)$ & $-.008(.009)$ & $-.014(.009)$ \\
\hline Ambiguity aversion $* c=2$ & $-.020 *(.012)$ & $-.033(.021)$ & $-.021(.014)$ & $-.030 * *(.013)$ & $-.011(.013)$ \\
\hline Belief on entrants relative to capacity & $.040 * * *(.012)$ & $.024(.024)$ & $.038 * * *(.014)$ & $.041 * * *(.014)$ & $.041 * * *(.015)$ \\
\hline Belief on entrants relative to $c=2$ & $-.024(.017)$ & $-.031(.034)$ & $-.005(.022)$ & $-.027(.022)$ & $-.015(.022)$ \\
\hline Belief on rank within own generation in $\mathrm{PT}$ & $-.070 *(.042)$ & $-.149 * *(.074)$ & $.029(.060)$ & - & $-.090 *(.048)$ \\
\hline “* $c=2$ & $-.195 * * *(.058)$ & $-.230 *(.118)$ & $-.259 * * *(.080)$ & - & $-.214 * * *(.066)$ \\
\hline Belief on rank better than other generation in PT & $.047(.084)$ & $.095(.149)$ & 028(.091) & - & $.045(.088)$ \\
\hline "*c=2 & $.143 *(.083)$ & $.301 * * *(.096)$ & $.083(.100)$ & - & $.146 \#(.090)$ \\
\hline Majority of juniors & $.086(.058)$ & $.056(.078)$ & $.213 * * *(.082)$ & $.027(.079)$ & $.146 * *(.072)$ \\
\hline Majority of juniors $* c=2$ & $-.040(.072)$ & $.001(.092)$ & $-.209(.219)$ & $.023(.120)$ & $-.117(.107)$ \\
\hline Majority of seniors & $-.001(.056)$ & $.023(.094)$ & $.034(.061)$ & $-.061(.072)$ & $.061(.083)$ \\
\hline Majority of seniors $* c=2$ & $.085(.065)$ & $.017(.160)$ & $.050(.075)$ & $.178 * *(.077)$ & $-.044(.122)$ \\
\hline Capacity of market $=2$ & $-.582 * * *(.128)$ & $-.865 * * *(.100)$ & $-.688 * * *(.146)$ & $-.633 * * *(.143)$ & $.052(.235)$ \\
\hline Capacity of market $=4$ & $-.248 * * *(.047)$ & $-.253 * * *(.075)$ & $-.251 * * *(.062)$ & $-.261 * * *(.056)$ & $-.232 * * *(.067)$ \\
\hline Period & $-.002(.003)$ & $-.002(.004)$ & $-.003(.003)$ & $.003(.010)$ & $-.010(.009)$ \\
\hline First period & $.137(.048)$ & $.121(.075)$ & $.161 * * *(.058)$ & $.138 * *(.067)$ & $.125(.080)$ \\
\hline Control for Order & Yes & Yes & Yes & Yes & Yes \\
\hline Control for multiple switches & Yes & Yes & Yes & Yes & Yes \\
\hline Control for demographics (male, supervisory fcts) & Yes & Yes & Yes & Yes & Yes \\
\hline $\mathrm{N} / \mathrm{Nb}$ clusters & $1440 / 80$ & $720 / 40$ & $720 / 40$ & $720 / 80$ & $720 / 80$ \\
\hline Log-pseudolikelihood & -779.986 & -382.638 & -351.583 & -396.933 & -374.913 \\
\hline Wald Chi ${ }^{2}$ & 178.91 & 136.50 & 297.72 & 126.14 & 120.64 \\
\hline Prob $>\mathrm{Chi}^{2}$ & .000 & .000 & .000 & .000 & .000 \\
\hline Pseudo- $\mathrm{R}^{2}$ & .156 & .198 & .207 & .139 & .190 \\
\hline
\end{tabular}


Table 4 (continued). Determinants of the entry decision in Part 2

\begin{tabular}{|c|c|c|c|c|}
\hline $\begin{array}{l}\text { Independent variable: } \\
\text { Decision to enter }\end{array}$ & $\begin{array}{l}\text { Random tr. } \\
\text { Juniors (6) }\end{array}$ & $\begin{array}{l}\text { Random tr. } \\
\text { Seniors (7) }\end{array}$ & $\begin{array}{l}\text { Performance tr. } \\
\text { Juniors (8) }\end{array}$ & $\begin{array}{l}\text { Performance tr. } \\
\text { Seniors (9) }\end{array}$ \\
\hline Performance treatment & - & - & - & - \\
\hline Performance treatment $* c=2$ & - & - & - & - \\
\hline Senior & - & - & - & - \\
\hline Senior $* c=2$ & - & - & - & - \\
\hline Risk preferences & $.044 * *(.021)$ & $-.012(.012)$ & $.013(.019)$ & $-.011(.009)$ \\
\hline Risk preferences $* c=2$ & $.059 \#(.037)$ & $.029 *(.017)$ & $.104 * *(.042)$ & $.015(.014)$ \\
\hline Ambiguity aversion & $-.004(.014)$ & $-.010(.010)$ & $.001(.014)$ & $-.019 * *(.007)$ \\
\hline Ambiguity aversion $* c=2$ & $-.036 *(.021)$ & $-.031 *(.016)$ & $-.030(.026)$ & $-.011(.014)$ \\
\hline Belief on entrants relative to capacity & $.027(.026)$ & $.039 * *(.017)$ & $.018(.035)$ & $.039 * *(.016)$ \\
\hline Belief on entrants relative to $c=2$ & $-.047(.044)$ & $-.014(.028)$ & $-.019(.053)$ & $.003(.024)$ \\
\hline Belief on rank within own generation in PT & - & - & $-.165 *(.89)$ & $.011(.060)$ \\
\hline$" * c=2$ & - & - & $-.225 *(.124)$ & $-.243 * * *(.078)$ \\
\hline Belief on rank better than other generation in $\mathrm{PT}$ & - & - & $.042(.163)$ & $.031(.090)$ \\
\hline " * $c=2$ & - & - & $.335 * * *(.121)$ & $.087(.097)$ \\
\hline Majority of juniors & $-.021(.107)$ & $.203 * *(.101)$ & $.118(.106)$ & $.231 * * *(.077)$ \\
\hline Majority of juniors $* c=2$ & $.121(.147)$ & $-.243(.306)$ & $-.036(.128)$ & $-.346(.285)$ \\
\hline Majority of seniors & $.007(.157)$ & $-.041(.085)$ & $.013(.111)$ & $.142(.108)$ \\
\hline Majority of seniors $* c=2$ & $.217(.153)$ & $.110(.114)$ & $-.119(.249)$ & $-.128(.172)$ \\
\hline Capacity of market $=2$ & $-.823 * * *(.166)$ & $-.756 * * *(.140)$ & $-.785 * * *(.262)$ & $.238(.242)$ \\
\hline Capacity of market $=4$ & $-.331 * * *(.083)$ & $-.205 * *(.083)$ & $-.223 * *(.106)$ & $-.254 * * *(.096)$ \\
\hline Period & $.022(.013)$ & $-.015(.018)$ & $-.008(.011)$ & $-.014(.017)$ \\
\hline First period & $.221 * * *(.085)$ & $.070(.106)$ & $.092(.139)$ & $.155^{*}(.087)$ \\
\hline Control for Order & Yes & Yes & Yes & Yes \\
\hline Control for multiple switches & Yes & Yes & Yes & Yes \\
\hline Control for demographics (male, supervisory fcts) & Yes & Yes & Yes & Yes \\
\hline $\mathrm{N} / \mathrm{Nb}$ clusters & $360 / 40$ & $360 / 40$ & $360 / 40$ & $360 / 40$ \\
\hline Log-pseudolikelihood & -191.859 & -182.630 & -183.282 & -165.915 \\
\hline Wald $\mathrm{Chi}^{2}$ & 105.26 & 114.93 & 80.17 & 239.44 \\
\hline Prob $>\mathrm{Chi}^{2}$ & .000 & .000 & .000 & .000 \\
\hline Pseudo-R ${ }^{2}$ & .183 & .190 & .241 & .237 \\
\hline
\end{tabular}

Note: Probit models with robust standard errors clustered at the individual level. *** indicate significance at the .001 level, $* *$ at the .005 level, and

$*$ at the .10 level. The variables for multiple switches in the risk elicitation task and for gender are never significant. The dummy variable for the order of treatments is only significant (at the .10 level, negative) in the regression reported in column (6). 
Table 5. Entrants' average expected payoffs per period in ECU in Part 2, by treatment, generation, and group composition

\begin{tabular}{|c|c|c|c|c|c|c|c|c|}
\hline \multirow{2}{*}{$\begin{array}{l}\text { Group } \\
\text { composition }\end{array}$} & \multicolumn{4}{|c|}{ Random treatment } & \multicolumn{4}{|c|}{ Performance treatment } \\
\hline & $\mathrm{N}$ & Total & Juniors & Seniors & $\mathrm{N}$ & Total & Juniors & Seniors \\
\hline $10 \mathrm{~J}$ & 78 & 231.84 & 231.84 & - & 75 & 246.95 & 246.95 & - \\
\hline $7 \mathrm{~J}-3 \mathrm{~S}$ & 78 & 315.57 & 277.77 & 383.07 & 79 & 323.21 & 243.85 & $467.77 * * *$ \\
\hline $5 \mathrm{~J}-5 \mathrm{~S}$ & 161 & 299.85 & 264.35 & $333.21 \#$ & 154 & 332.15 & 322.77 & 339.96 \\
\hline $3 \mathrm{~J}-7 \mathrm{~s}$ & 82 & 293.52 & 263.24 & 306.80 & 83 & 286.18 & 269.55 & 292.17 \\
\hline $10 \mathrm{~S}$ & 77 & 329.50 & - & 329.50 & 82 & 320.64 & - & 320.64 \\
\hline All groups & 476 & 294.99 & 256.16 & $331.60 * * *$ & 473 & 307.08 & 272.85 & $336.35^{* *}$ \\
\hline
\end{tabular}

Note: $\mathrm{J}$ for juniors and $\mathrm{S}$ for seniors. The numbers in italics indicate when the generation is in minority in the group.

Two-tailed two-sample t-tests have been performed to test the equality of mean expected payoffs by generation, for each group composition and each treatment. $* * *$ indicate significance at the .001 level, ** at the .005 level, * at the .10 level, and ${ }^{\#}$ at the .102 level.

Table 6. Average payoffs per period in ECU in Part 2, by treatment, generation, and group composition

\begin{tabular}{|c|c|c|c|c|c|c|c|c|}
\hline \multirow{3}{*}{$\begin{array}{l}\text { Group } \\
\text { composit. }\end{array}$} & \multicolumn{8}{|c|}{ Random treatment } \\
\hline & \multicolumn{4}{|c|}{ All participants } & \multicolumn{4}{|c|}{ Entrants } \\
\hline & $\mathrm{N}$ & Total & Juniors & Seniors & $\mathrm{N}$ & Total & Juniors & Seniors \\
\hline $10 \mathrm{~J}$ & 120 & 175 & 175 & - & 78 & 269.23 & 269.23 & - \\
\hline $7 \mathrm{~J}-3 \mathrm{~S}$ & 120 & 175 & 200 & 116.67 & 78 & 269.23 & 336 & 150 \\
\hline $5 \mathrm{~J}-5 \mathrm{~S}$ & 240 & 164.58 & 206.67 & 122.5 & 161 & 245.34 & 317.95 & 177.11 \\
\hline $3 \mathrm{~J}-7 \mathrm{~S}$ & 120 & 158.33 & 161.11 & 157.14 & 82 & 231.71 & 232 & 231.58 \\
\hline $10 \mathrm{~S}$ & 120 & 179.17 & - & 179.17 & 77 & 279.22 & - & 279.22 \\
\hline \multirow[t]{2}{*}{ All groups } & 720 & 169.44 & 190 & 148.89 & 476 & 256.30 & 296.10 & 218.78 \\
\hline & \multicolumn{8}{|c|}{ Performance treatment } \\
\hline $10 \mathrm{~J}$ & 120 & 187.5 & 187.5 & - & 75 & 300 & 300 & - \\
\hline $7 \mathrm{~J}-3 \mathrm{~S}$ & 120 & 170.83 & 220.24 & 55.56 & 79 & 259.49 & 362.75 & $71.43^{*}$ \\
\hline $5 \mathrm{~J}-5 \mathrm{~S}$ & 240 & 179.17 & 131.67 & 226.67 & 154 & 279.22 & 225.71 & 323.81 \\
\hline $3 \mathrm{~J}-7 \mathrm{~S}$ & 120 & 154.17 & -66.67 & $248.81 * * *$ & 83 & 222.89 & -109.09 & $342.62 * *$ \\
\hline $10 \mathrm{~S}$ & 120 & 158.33 & - & 158.33 & 82 & 231.71 & - & 231.71 \\
\hline All groups & 720 & 171.53 & 151.11 & 191.94 & 473 & 261.10 & 249.54 & 270.98 \\
\hline
\end{tabular}

Note: $\mathrm{J}$ for juniors and $\mathrm{S}$ for seniors. The numbers in italics indicate when the generation is in minority in the group. Two-tailed two-sample t-tests have been performed to test the equality of mean payoffs by generation, for each group composition and each treatment. $* * *$ indicate significance at the .001 level, $* *$ at the .005 level, and * at the .10 level. 


\section{APPENDIX 1. Instructions (translated from French)}

We thank you for participating in this experiment on decision-making. Throughout the session, your earnings are expressed in ECU (Experimental Currency Units) with the following conversion rate:

$$
100 \mathrm{ECU}=\mathrm{CHF} 2
$$

This session consists of several parts. We have distributed the instructions for the first part; you will receive the instructions for the next parts once the first part will be completed. Please read these instructions carefully.

At the end of the session, your payoffs in ECU from the different parts will be added up and converted into Swiss Francs. You will also receive a show-up fee of CHF15. You will be paid individually and in private.

Throughout the session, it is strictly forbidden to communicate with the other participants.

\section{Part 1}

Part 1 consists in two sub-parts.

\section{$\circ$ Description of the $1^{\text {st }}$ sub-part}

Imagine an urn that contains 10 balls, 5 yellow balls and 5 blue balls.

You must make 20 successive choices between extracting a ball from this urn with replacement (for each decision, there are always the same 10 balls in the urn) or earning a certain amount of money.

If you extract a yellow ball from the urn, you earn $500 \mathrm{ECU}$; if you extract a blue ball from the urn, your earn 0 ECU.

We propose you 20 certain amounts possible, from $25 \mathrm{ECU}$ to $500 \mathrm{ECU}$; the certain amount increases by $25 \mathrm{ECU}$ at each new decision.

You must indicate on your computer screen for each decision if you prefer receiving the certain amount or extracting a ball from the urn.

The following Table will appear on your screen:

\begin{tabular}{|r|l|l|}
\hline 1 & O I choose the certain amount of 25 ECU & O I choose to extract a ball \\
2 & O I choose the certain amount of 50 ECU & O I choose to extract a ball \\
3 & O I choose the certain amount of 75 ECU & O I choose to extract a ball \\
4 & O I choose the certain amount of 100 ECU & O I choose to extract a ball \\
5 & O I choose the certain amount of $125 \mathrm{ECU}$ & O I choose to extract a ball \\
6 & O I choose the certain amount of 150 ECU & O I choose to extract a ball \\
7 & O I choose the certain amount of 175 ECU & O I choose to extract a ball \\
8 & O I choose the certain amount of 200 ECU & O I choose to extract a ball \\
9 & O I choose the certain amount of 225 ECU & O I choose to extract a ball \\
10 & O I choose the certain amount of 250 ECU & O I choose to extract a ball \\
11 & O I choose the certain amount of 275 ECU & O I choose to extract a ball \\
12 & O I choose the certain amount of 300 ECU & O I choose to extract a ball \\
13 & O I choose the certain amount of 325 ECU & O I choose to extract a ball \\
14 & O I choose the certain amount of 350 ECU & O I choose to extract a ball \\
15 & O I choose the certain amount of 375 ECU & O I choose to extract a ball \\
16 & O I choose the certain amount of 400 ECU & O I choose to extract a ball \\
17 & O I choose the certain amount of 425 ECU & O I choose to extract a ball \\
18 & O I choose the certain amount of 450 ECU & O I choose to extract a ball \\
19 & O I choose the certain amount of 475 ECU & O I choose to extract a ball \\
20 & O I choose the certain amount of 500 ECU & O I choose to extract a ball \\
\hline
\end{tabular}




\section{○escription of the $2^{\text {nd }}$ sub-part}

This sub-part is similar to the previous one, except that we use a new urn and you do not know its composition.

You must again make 20 decisions between receiving a certain amount or extracting a ball from the new urn. The certain amounts are the same as in the previous sub-part. The new urn also contains 10 balls, yellow balls and blue balls.

However in contrast with the previous sub-part, you do not know the number of yellow balls and blue balls in the urn.

\section{How are payoffs determined in this part?}

At the end of the session, the computer program will randomly draw one of your 20 decisions in the first sub-part and one of your 20 decisions in the second sub-part. Each decision has the same chance to be selected. You should therefore give the same attention to each decision.

For each randomly selected decision:

- If you have chosen the certain amount, we will add this amount to your other earnings in the experiment;

- If you have chosen the random draw, the computer program will extract one ball. If it is yellow, $500 \mathrm{ECU}$ will be added to your other payoffs; if it is blue, you will earn 0 ECU.

If you have any question regarding these instructions, please raise your hand and do not speak aloud. We will answer your questions in private.

\section{Part 2 (distributed after Part 1 was completed)}

You receive an initial endowment of 500 ECU in this part.

This part consists of 18 periods during which you must decide to enter or not a market.

These 18 periods are grouped in two sequences of 9 periods each.

- The "random draw" sequence,

- The "performance" sequence.

Your computer screen will indicate if you start with the Random sequence or the Performance sequence. The two sequences will succeed automatically. You are informed on your screen of the current sequence.

\section{Description of the Random sequence}

\section{- Description of each period}

1. At the beginning of each of the 9 periods of this sequence, you are grouped with 9 other participants. You do not receive any information about these participants except for their generation («junior» ou «senior»).

2. Then, each group member is informed on the value of a number " $\mathrm{C}$ ". Imagine that $\mathrm{C}$ is the market capacity, i.e. the number of participants who can make profits on this market. $\mathrm{C}$ can take values 2, 4 or 6 . For example, if $\mathrm{C}=4$, then 4 participants who decided to enter the market will be able to make benefits. The other participants who decided to enter will lose $500 \mathrm{ECU}$.

3. Next, we will ask you to estimate the number of the other group members who will enter the market (between 0 and 9, you excluded).

4. Then, you have to decide if you enter or not the market.

* If you decide not to enter, you do not earn anything and you do not lose anything either.

* If you enter, your payoff depends on the market capacity and your rank among the participants from your group who have decided to enter (the "entrants"). We explain below how your rank is assigned to you.

The Table that has been distributed indicates for each market capacity the payoffs of the entrants (in ECU) according to their rank. Please look at this Table. 
For example, suppose the market capacity is $2(C=2)$ and you have decided to enter. If you have the first rank among the entrants, you earn 1900 ECU. If you have the second rank among the entrants, you earn 1100 ECU. If you have the third rank and beyond, you lose $500 \mathrm{ECU}$.

5. At the end of each period, you are informed on the number of other members of your group who have decided to enter the market during this period (between 0 and 9).

\section{o Determination of ranks}

In the Random sequence, the ranks of the entrants are randomly determined by the computer program. For example, if there are 5 individuals who decide to enter the market in a period, the program will assign randomly a rank between 1 and 5 to these entrants. If the market capacity is $4(\mathrm{C}=4)$ and your randomly determined rank is 5 , then you make a loss.

You do not know your rank when making your entry decision.

- What does change from one period to the other in this sequence?

- the composition of your group of 10 participants,

- $\quad$ the market capacity, C (i.e. the number of entrants who can make on the market),

- the payoffs associated with each rank as indicated in the Table we have distributed. We invite you to consult this Table throughout the game,

- $\quad$ your rank if you decide to enter the market.

\section{Description of the «performance» sequence}

This sequence consists also of nine periods. Each period is similar to the Random sequence except for one thing: the ranks of the entrants do not depend of a random draw any more.

The ranks of the entrants depend on their relative performance in a quiz of general economic knowledge that will be presented to you in Part 3.

For a given period, the computer program will compare at the end of the session the performance in the quiz of each entrant on the market. The entrant who will have given on average the answers the closest to the correct answers will get the first rank. The entrant who will have given on average the worst answers to the quiz will get the last rank among the entrants. In case of ties, ranks are assigned randomly among the ex-aequo entrants.

In the quiz, the questions are similar to the following ones:

* What is the current rank of Switzerland in the world in terms of Gross Domestic Product?

* Which percentage of its GDP does the deficit of Greece represent in 2009?

Since the quiz is administered in the next part, you do not know your rank when you decide to enter the market or not. You can just have a belief on your rank.

\section{Determination of payoffs in this part}

At the end of the session, the computer program will select randomly one period out of 18 . Each period has the same chance to be selected for payment. It is therefore important to give the same attention to each of your 18 decisions.

- For this period, the program calculates the number of participants who decided to enter the market in your group of 10 participants. If your prediction of the number of entrants in this period is exact, you earn $100 \mathrm{ECU}$.

- If you decided to enter, the program assigns you a rank and compares your rank to the rank of the other entrants in your group. If your rank is lower or equal to the capacity of the market, $\mathrm{C}$, you make a benefit and you earn the amount corresponding to your rank for this capacity. If your rank is higher than the market capacity you lose 500 ECU.

- If you decided not to enter, you do not earn and you do not lose anything.

- Your total payoff in this part is therefore equal to: 
500 ECU (your initial endowment)

+100 ECU if your prediction of the number of entrants in the selected period is exact

+ the ECU earned /or/ the ECU lost due your decision to enter the market in the selected period.

At the end of the session, you are informed on your payoffs. If you entered the market, we also inform you about your rank among the entrants.

You are not informed on whether, in this period, your rank depended on a random draw or on your relative performance in the quiz.

We invite you to read again these instructions and to answer the comprehension questionnaire that has been distributed. If you have any question, please raise your hand and we will answer your questions privately.

Table for the determination of payoffs in Part 2 (in ECU)

\begin{tabular}{|c|c|c|c|}
\hline \multirow{2}{*}{$\begin{array}{l}\text { Rank among the } \\
\text { entrants }\end{array}$} & \multicolumn{3}{|c|}{ Market capacity, C } \\
\hline & $\mathrm{C}=2$ & $\mathrm{C}=4$ & $\mathrm{C}=6$ \\
\hline 1 & 1,900 & 1,400 & 900 \\
\hline 2 & 1,100 & 900 & 700 \\
\hline 3 & -500 & 500 & 500 \\
\hline 4 & -500 & 200 & 400 \\
\hline 5 & -500 & -500 & 300 \\
\hline 6 & -500 & -500 & 200 \\
\hline 7 & -500 & -500 & -500 \\
\hline 8 & -500 & -500 & -500 \\
\hline 9 & -500 & -500 & -500 \\
\hline 10 & -500 & -500 & -500 \\
\hline
\end{tabular}

Note: The market capacity indicates the number of participants in the group of 10 who can make profits if entering the market. $\mathrm{C}=2$ indicates that 2 entrants can make profits; $\mathrm{C}=4$ indicates that 4 entrants can make profits; $\mathrm{C}=6$ indicates that 6 entrants can make profits.

Please refer to this Table during the 18 periods of this part.

\section{Part 3 (distributed after Part 2 was completed)}

This part consists of 4 questions on general economic knowledge.

Your performance in this quiz allows you to make additional earnings. It also serves to the determination of your performance rank in the previous part.

\section{○ The task}

- For each question, you must provide an answer that is comprised in between 0 and 100 (included) by moving a scrollbar on your screen.

- You must also define a confidence interval for your answer. Please indicate a minimum value such that you think that the correct answer cannot be lower than this value. Please also indicate a maximum value such that the correct answer cannot be higher than this value. Your answer must be included in this interval, otherwise it will be rejected by the program.

Here is an example of the scrollbar that will be displayed on your screen below each question:

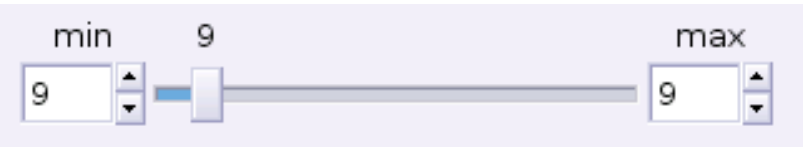




\section{- Determination of payoffs in this Part}

For each question, you receive an initial endowment of 100 ECU.

Your payoff for each question is determined by the size of the interval that you have defined and the inclusion of the correct answer in this interval.

Thus,

- If the interval that you have defined does not include the correct answer that has been registered in the computer program, you lose your $100 \mathrm{ECU}$ for this question.

- If the interval includes the correct answer, your payoff for this question is equal to: 100 ECU - the width of the chosen interval.

For example, suppose the correct answer to a question is 19.

a) If your answer is 12 and your interval is defined between 10 and 20 (its width is 10), your payoff is: 100 $10=90$ ECU.

b) If your answer is 12 and your interval is defined between 5 and 50, your payoff is: $100-45=55$ ECU.

c) If your answer is 12 and your interval is defined between 10 and 15, you lose your 100 ECU.

Therefore, the more precise your answers, the higher your payoffs.

Your total payoff in this part is given by the sum of your payoffs for the four questions.

\section{How are calculated the ranks of the entrants in the Performance sequence of the precious part?}

We calculate your « distance index».

This distance index is equal to the mean difference in absolute value between the correct answers and the answers you have given to the four questions in this part. The intervals you have indicated are not taken into account in the calculation of your distance index.

The better your responses, the lower (thus, the better) your distance index. An index of 0 means that all your answers are exact.

To determine the entrants' ranks in their group in each period of the Performance sequence of the previous part:

- The computer program compares and ranks the entrants' distance indices in each group;

- It assigns ranks to entrants as a result of this comparison, from the best rank (the $1^{\text {st }}$ ) assigned to the entrant with the lowest distance index in his group to the last rank assigned to the entrant with the highest index.

Let's take the previous example where the correct answer is 19.

a) If your answer is 12 , then the difference in absolute value between the correct answer and your answer is equal to: $|19-12|=7$.

b) If your answer is 30 , then the difference is: $|19-30|=11$.

The distance index is the mean value of these differences in the four questions.

\section{Information}

At the end of the session,

- You are informed on your total payoff in this part;

- You are informed of your distance index only if you ask to know it in a further part.

If you have any question, please raise your hands and we will answer your questions in private. 
Part 4 (distributed after Part 3 was completed)

Please indicate, among the proposed categories, your expectations about:

- your distance index (i.e. the mean difference in absolute value between the correct answers and your answers to the four questions in the previous part)

- the average distance index of the 10 juniors in the session

- the average distance index of the 10 seniors in the session

- your performance rank in the quiz among the 10 participants of your generation (i.e. juniors or seniors) given by the comparison between the distance indices

- your performance rank in the quiz among the 20 participants in the session.

Each correct prediction pays you 50 ECU.

At the end of the session, you will be only informed of your total payoff in this part.

Part 5 (distributed after Part 4 was completed)

1) Please indicate on your computer screen if you are willing to know or not to know, at the end of the session, your distance index.

2) Please indicate if you are willing to know or not to know, at the end of the session, your performance rank in the quiz among the 20 participants given by the comparison of the distance indices.

3) Please indicate if you accept or not that we disseminate to the other participants the three following pieces of information:

- the number of times (between 0 and 9) you decided to enter the market in the Performance sequence in Part 2 (when your rank depended on your relative performance)

- your performance rank in the quiz among the 20 participants

- your generation.

A Table will disseminate anonymously these pieces of information relative to those who have accepted this dissemination. In this Table, you will not be able to see any information concerning you personally.

After answering a final questionnaire, you will be informed on your screen of your earnings in each part of this session.

Please remain seated until we invite you to leave your cubicle and do not communicate with the other participants. 
APPENDIX 2. The experimental laboratory in the company

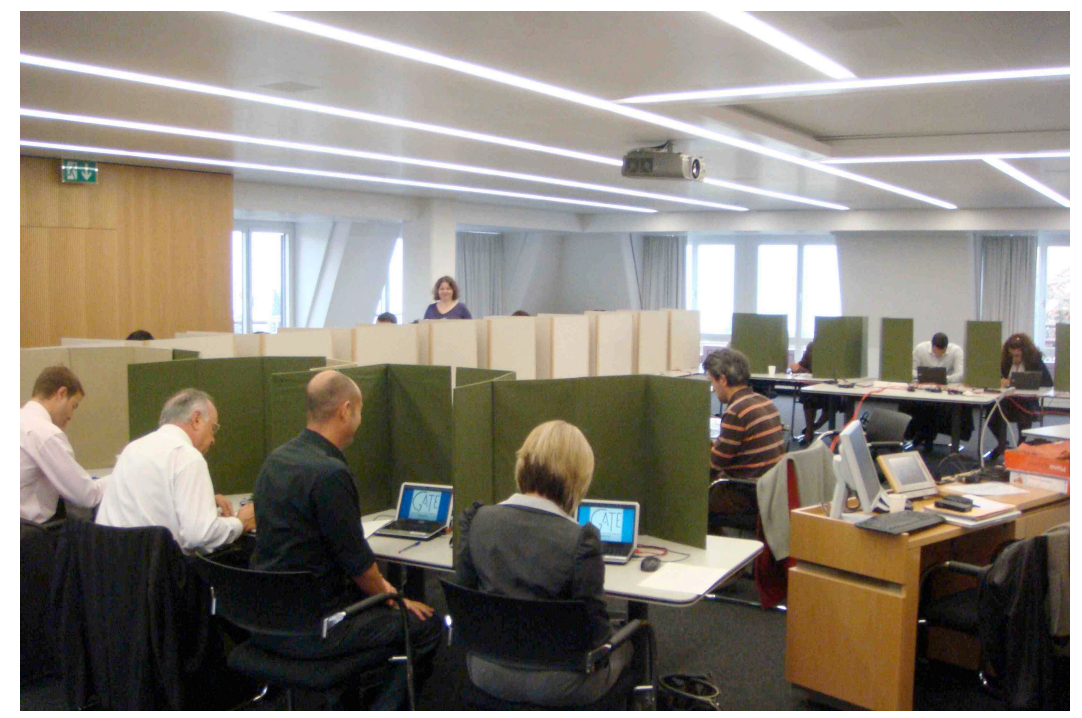

Note: The different colors of the dividers were not associated with generations 